\title{
Pragmatic Competence: Difficulties faced by Pakistani EFL Learners
}

\author{
* Muhammad Ashraf
}

** Dr. Sikander Ali (Corresponding Author)

\begin{abstract}
The study investigates the pragmatic knowledge; pragmatic competence level as well as speech act strategies used by Pakistani EFL learners. It reveals that Master level English language learners are unable to produce and comprehend the intended meanings in the target language. As a result, pragmatic failure and misunderstanding occurred. Pragmatic comprehension and production is essential for effective communication especially for EFL learners in this modern age where people have to communicate cross-culturally as English is being used as lingua franca internationally. The study explores the problems faced by EFL learners in comprehending and producing the correct speech acts in English. The study used two data collection tools: a WDCT in which speech acts of refusal and apology are used to find out pragmatic competence level and difficulties faced by Pakistani EFL learners. A Likert Scale questionnaire is used to know about the views and suggestions of the Pakistani EFL learners about the teaching and learning environment regarding the pragmatics. The data of speech acts of refusal is analyzed qualitatively according to the taxonomy of Beebe, keeping in view frequency, shift and content of semantic formulas. While the data of speech acts of apology is analyzed according to the speech act strategies of Cohen. Data collected through the Likert scale questionnaire is analyzed quantitatively. The study finds out that pragmatic competence level of Pakistani EFL learners is very low as well as they have to face many difficulties which result in pragmatic failure. Findings of the study show that Pakistani EFL learners lack knowledge of pragmatics in the target language. EFL learners acknowledged that pragmatic knowledge is very important for effective communication and it should be an integral part of syllabus and classroom activities.
\end{abstract}

Keywords: Pragmatic Competence, EFL Learners, Pragmatic Failure.

Research Background

The study aims to find out the difficulties faced by Pakistani EFL learners in production and comprehension of intended meanings as well as their pragmatic competence level. As Pragmatic comprehension and production is essential for effective communication in the target language. EFL learners, instead of being fluent and grammatical correct, have to face a lot of problems in comprehension and production of effective communication in the target language. So keeping in view the importance of pragmatic knowledge for effective communication in the target language, the study investigates the difficulties faced by Pakistani EFL learners at master level, in comprehending and producing the intended meanings. The study uses two data collection tools, a WDCT: consisting speech acts of refusal and apology are used to find out the pragmatic knowledge, pragmatic competence level as well as the difficulties faced by English learners in Pakistan. A Likert scale questionnaire is distributed among the master level learners to know about their views and suggestions regarding the pragmatic competence in the target language. The study is mixed in nature as collected data is analyzed qualitatively as well as quantitatively.

\section{Statement of the Problem}

In Pakistan, English is learned as a foreign language, therefore learners have to face a lot of problems in comprehending the native speaker's verbal or written messages in its true sense. Nowadays just leaning of vocabulary and grammatical rules is not considered enough for effective communication but it is essential to have knowledge of pragmatics. Because of the geographical, political, social, religious and cultural differences it becomes very difficult for the students to pick the intended meaning so as a result ambiguity and misunderstanding puzzles the learners while communicating in the target language. Syllabus designers ignore the historical and cultural aspects of the target

* University of Lahore, Lahore, Pakistan Email: dogerashraf@gmail.com

** University of Lahore, Lahore, Pakistan Email: sikandar.ali@ell.uol.edu.pk 
language. Teachers do not discuss the local or native context of the target language in the classroom. Therefore, it becomes very difficult for Pakistani EFL learners to comprehend the intended meanings instead of having a lot of linguistic competence. So the present study highlights the problems faced by Pakistani EFL learners in comprehending the pragmatic meanings in the target language.

\section{Relations hip between Communication and Pragmatics}

Non-native speakers can speak English language fluently but they have to face difficulties because of cultural differences, and they seem doubtful that this happens because of their poor pronunciation and accent problems but the reality is opposite and they spend a lot of time in copying the pronunciation of the native speakers. In a native setting the pragmatic mistake is considered more serious than the grammatical mistake as it is discussed by (Bardovi-Harlig, 1996). EFL learner's pragmatic competence in L1 is learned naturally by the socio-cultural environment in which they are born while individuals will and preference becomes the reason behind the pragmatic competence in L2. All the language users have a lot of socio-cultural knowledge of that society in which they flourish, for example it may be regarding everyday living, living conditions, and interpersonal relations, use of the body language, social conventions, traditions and the ritual behavior (Common European Framework). Different cultures have their own different traditions and customs for greetings, apologizing, refusing and complementing. So to conclude it can be said that for purposeful and effective communication in the target language, pragmatic competence is essential without it misunderstanding and pragmatic failure occurs.

\section{Importance of Pragmatic Competence}

For the effective communication, it is necessary to get information about the target culture and social norms along with the grammatical ability, as without the socio-cultural background into the target language the intended message can't be delivered and comprehended. (Kasper \& Rose, 2002) describe that the ability to find out the most appropriate utterances in accordance with a given context and the selection of linguistic forms according to the situation and matter are most important components of the pragmatic competence. As cited by Brown \& Mey $(2006,2009)$ points out that cross cultural communication because of the differences in culture and society norms and traditions may face a lot of misunderstanding among its users. Importance of pragmatic competence can be identified through this example in Japanese context it is enough to say "I am sorry" but in other cultures such as in Jordan alone "I am sorry" is not considered enough and the offender have to explain the offence (Bataineh \& Bataineh, 2008).

\section{Research Questions}

1. Why do Pakistani EFL learners often face difficulties in comprehending the intended meanings?

2. What types of difficulties are faced by Pakistani EFL learners in comprehending the intended meaning?

\section{Lite rature Review}

Pragmatic competence is an umbrella term used for the knowledge of user or learner of a language: it includes the organization and arrangement of the words for communication purposes keeping in view the cultural and social contexts as it is defined by (Council of Europe, 2001). Pragmatic competence is an individual's capability of using language to achieve successfully a particular purpose and be able to comprehend the spoken or written language in context. Canale (1987) expanded the boundary of the pragmatic competence including the pragmatic knowledge necessary for the appropriate communication, and the knowledge of social conventions for perfect contextual communication. The study carried out by (Kasper \& Rose, 2002) discusses the pragmatic competence in the target language that it investigates the way through which the users produce and comprehend the target language. According to them the pragmatic competence in the target language involves the investigation of the EFL learner's capabilities of development and performance in the target language.

\section{Cross-Cultural Pragmatic Failure:}

As (Miller, 1974) explains that often language users fail to comprehend the interlocutor not because they can't understand the words whereas the real problem is that they fail to comprehend the intention of the speaker that what the speaker really wants to convey through his words. (Jenny Thomas) used the term "Cross-cultural" for all the native and non-native speakers who have different linguistic and cultural backgrounds. As each culture is unique in itself, then speaker's application of his cultural norm on the L2 setting can be harmful. Linguistics competence is generally known as grammatical 
competence, which does not exist within a particular context, it is the knowledge of phonology, intonation, syntax and semantics while on the other hand pragmatic competence is the ability of a language user to produce and comprehend the language in the context. As (Leech, 1983) differentiates between linguistic and pragmatic competence: linguistic competence is formal grammatical knowledge of a language while pragmatic competence refers to the contextual use of language for specific purpose in which speaker conveys more than the words mean.

\section{Reas ons behind Cross-cultural pragmatic failure :}

According to (Bardovi-Harlig, 1996) that EFL learner's bad performance is due to the factor i.e. that they are not provided with the relevant input or the input sources are not relevant to the learners, or it may be that due to the lack of grammatical competence or pragmatic knowledge it becomes difficult for them to perceive the relevant input in the language classrooms. It is observed that EFL learners have to face a lot of difficulties and their understanding in pragmatics is limited. Pragmatic failure might also happen because of the target culture' incomprehensibility and distance between two cultures which causes the learners lack of interest, so it is the duty of the teacher to discuss the target culture vividly, make it interesting and reachable. (O'Keeffe et al., 2011) argues that EFL learners don't commit pragmatic errors intentionally but it is their possession with the ir native culture and norms.

\section{Interlanguage Pragmatics:}

Interlanguage is the discipline that deals linguistic issues regarding the acquisition, comprehension and use of speech acts in a non-native language, as it is defined Larry Selinker, and American professor of applied linguistics. (Kasper and Dahl, 1991) define the discipline of inter language pragmatics as how a non-native user of a language acquires, comprehends and produces the pragmatics. As (Bardovi-Harling, 2002) points out that ILP is not a new discipline but it is underdeveloped area just like some other branches of linguistics. The way target language speakers acquire, produce and comprehend the pragmatics is the discipline which is defined as Inter language pragmatics (ILP) as it is defined by (Kasper and Dahl, 1991). The field in which linguists study the non-native speakers use of the language and how they acquire the second language is known as interlanguage pragmatics as defined by (Kasper and Blum-Kulka, 1993). It is evident that an advanced language learner may qualify examination scoring high level marks but at the same time the same individual may face a lot of difficulties in using the language in the real life-like situations. In a study carried out by (Blum-Kulka, House, and Kasper, 1989) concluded that advanced level leaners while communicating commit pragmatic errors and in another research (Bardovi-Harlig \& Hartford, 1997) it is recommended that in an EFL setting cross-cultural pragmatics needs special concentration.

\section{Speech Acts The ory:}

When people communicate, they not only produce utterances by forming grammatical structures and lexical items but they also perform actions through these utterances. And these utterances have different functions and effects according to the context and power of the speaker and the social distance between the speaker and the hearer. These utterances are called speech acts, and these speech acts are classified as performatives, compliments, acknowledgments, apology, invitation, promise, refusal or request. According to (Cutting, 2008) to grasp with the intended meaning and to recognize the aim of language the speech act theory was developed as it is mentioned by (O'Keeffe et al., 2011).

In performing these speech acts speakers expects that his intentions or intended meanings will be perceived by the listener. Speech acts are divided into three types:

a) Locutionary: locutionary act is meaningful linguistic utterance which is produced by the speakers or writers

b) Illocutionary: Illocutionary act or illocutionary force is the real intention of the speakers or the writer behind that linguistic utterance, as human beings don't use language without any purpose.

c) Perlocutionary: While performing an utterance we keep in mind that what will be the effect of his illocutionary force/utterance he has performed. This is known as perlocutionary effects or perlocutionary act. For example an utterance like this; (I'll see you later.)

This utterance may be a prediction, or a promise, or it can be a warning.

It is up to the hearer that how he interprets the speech acts while considering illocutionary force indicating device and felicity conditions. 


\section{Design of the Study}

This research explores the pragmatic competence level of the Pakistani EFL learners studying at master level. It is a mixed type study which employs both qualitative and quantitative means for data analysis. Mixed method is more authentic validas (Dornyei, 2007) suggests that studies which employ the mixed method have the more validity and they are concerned with the multiple audiences. So the study employs both quantitative and qualitative approaches for data collection and data analysis to fulfil the objectives of the study. Collected data is analyzed both qualitatively as well as quantitatively for the authenticity and validity of the results. Two data collection tools are used in this study: WDCT is used to know about the EFL learner's pragmatic knowledge, pragmatic competence level as well as difficulties they have to face in expressing the speech acts of apology and refusal. Data collected through WDCT is analyzed qualitatively according to content, shift and frequency of semantic formulas. Speech acts of refusal are analyzed and discussed in accordance with the semantic formulas of Beebe et al., (1990) as they are used in a research "Measuring Interlangauge Pragmatic Knowledge of Chinese EFL Learners" by Liu Jianda in (2004) at the "City University of Hong Kong". Classification and qualitative analysis of the Speech acts of apology are done in accordance with the classification strategies suggested by Cohen et al. (1986). Data collected through the Likert scale questionnaire is analyzed quantitatively by manual percentage.

\section{Data Collection Procedure:}

First of all the researcher sought the permission from the Head of the department of English of the University of Okara. After the grant of permission data were collected from the student from 23 may to 30 may 2019. WDCT was attempted by the 50 participant's while the Likert scale questionnaire was completed by the 100 students. A WDCT test is distributed among the participants to check their speech act strategies and their pragmatic knowledge as well as pragmatic competence level. Then the Likert scale questionnaire is distributed among the EFL learners to get their views and suggestions.

\section{Canale and Swain's Model:}

The study's theoretical framework is set in accordance with the communicative competence model of (Canale \& Swain 1980). As pragmatic competence is core part of their model of communicative competence. In their model they define pragmatic competence as sociolinguistics competence that is the use of language appropriately in the social context. A theoretical model of communicative competence was developed by (Canale and Swain, 1980) and then it was extended and more elaborated by (Canale, 1983). Main competencies of this model include:

a) It includes the semantics, phonology, syntax and vocabulary and generally known as grammatical competence.

b) How to use the language appropriately according to the real life-like situations is known as sociolinguistic competence.

c) Discourse competence is the knowledge of the correct use of the cohesion and coherence for the unified written and spoken pieces of the language.

d) Strategic competence is the ability of a language user in using the appropriate communication strategies for the effectiveness of the communication and to deal with the breakdowns in the conversations.

Canale and Swain's model refers pragmatic competence as sociolinguistic competence which includes the appropriateness of the form as well as the appropriateness of the meaning.

\section{Data Analysis \& Discussion}

The study, as mixed in nature, uses qualitative and quantitative methods for the analysis of the collected data. In this study two data collection tools are used. WDCT is used to find out the pragmatic competence level and difficulties faced by Pakistani EFL learners in comprehension and production of intended meanings. A Likert scale questionnaire consisting of fifteen questions is used to get the views and suggestions of Pakistani EFL learners regarding the pragmatic competence.

\section{Data Analysis of Speech Acts of Refusal:}

\section{Table No. 1}

Overall Analysis of Speech acts of Refusal:

\begin{tabular}{lllllll}
\hline Formulas & \multicolumn{2}{l}{50 Pakistani } & EFL learners & \multicolumn{3}{l}{37 American Native Speakers } \\
\cline { 2 - 7 } & Higher & Equal & Lower & Higher & Equal & Lower \\
& Status & Status & Status & Status & Status & Status \\
Direct Refusal & 33 & 55 & 74 & 89 & 100 & 24 \\
Regret & 17 & 19 & 22 & 4 & 0 & 0 \\
\hline
\end{tabular}




\begin{tabular}{|c|c|c|c|c|c|c|}
\hline Criticize & 0 & 2 & 1 & 0 & 0 & 0 \\
\hline Hesitation & 0 & 0 & 0 & 0 & 0 & 0 \\
\hline St. Empathy & 0 & 0 & 0 & 0 & 0 & 0 \\
\hline Pause Fillers & 0 & 0 & 0 & 2 & 8 & 2 \\
\hline St. Solidarity & 0 & 0 & 0 & 0 & 0 & 0 \\
\hline Excuse, Reason, explanation & 36 & 37 & 5 & 60 & 35 & 84 \\
\hline Wish & 0 & 0 & 1 & 0 & 0 & 0 \\
\hline Set Condition & 0 & 0 & 0 & 0 & 0 & 0 \\
\hline Request & 0 & 0 & 0 & 0 & 0 & 0 \\
\hline Gratitude & 1 & 4 & 4 & 36 & 76 & 6 \\
\hline Elaboration & 0 & 0 & 0 & 0 & 0 & 0 \\
\hline St. Pos. opinion & 0 & 0 & 0 & 0 & 0 & 0 \\
\hline Hedging & 0 & 0 & 0 & 0 & 0 & 0 \\
\hline Joke & 0 & 0 & 0 & 0 & 0 & 0 \\
\hline St. Frankness & 0 & 0 & 0 & 0 & 0 & 0 \\
\hline Topic Switch & 0 & 0 & 1 & 0 & 0 & 0 \\
\hline Saying I tried & 0 & 0 & 0 & 0 & 0 & 0 \\
\hline Let off the hook & 1 & 0 & 27 & 0 & 0 & 94 \\
\hline St. Alternative & 1 & 1 & 2 & 3 & 3 & 5 \\
\hline Unspecific or indefinite reply & 0 & 0 & 1 & 0 & 0 & 0 \\
\hline Postponement & 1 & 0 & 6 & 0 & 0 & 0 \\
\hline Promise of future acceptance & 3 & 0 & 11 & 0 & 0 & 0 \\
\hline St. of Philosophy & 0 & 1 & 0 & 0 & 0 & 0 \\
\hline Self-defense & 3 & 0 & 1 & 0 & 0 & 0 \\
\hline
\end{tabular}

Table is adopted from Beebe et al. (1990)

Analysis shows that Pakistani EFL learners committed a lot of mistakes while responding the speech acts of refusal in the target language. It became difficult for the students to comprehend the real speech acts. Because of the poor pragmatic comprehension the production level is also pathetic. Most of the participants misunderstood the speech acts and gave an irrelevant and wrong response. Many of them instead of refusing the statement accepted and did not refuse the speech act because they misunderstood the speech act. Overall $17 \%$ percent of the speech acts of refusal are inappropriate, misunderstood and in them speech act of refusal is not used directly and indirectly. And $2 \%$ percent of speech acts of refusal are left blank without giving any response. Most of the participants directly refused the situations without any gratitude, giving explanation or mentioning any reason or without an alternative solution.

\section{Results of Speech Acts of Refusal:}

Analysis of the data indicates that Pakistani EFL learners committed a lot of mistakes while responding the speech acts of refusal in the target language. It became difficult for the students to comprehend the real speech acts. Most of the participants misunderstood the speech acts and in response used the wrong speech acts which show that English learners comprehension and production level is very low. Some of them instead of refusing the statement accepted and did not refuse the speech acts because they misunderstood the speech acts. Many of the speech acts of refusal are inappropriate, misunderstood and in them speech act of refusal is not used directly and indirectly. A few speech acts of refusal are left blank without giving any response which also show the pragmatic failure of EFL learners. Most of the participants directly refused the situations without any gratitude, giving explanation or mentioning any reason.

\section{Discussion on the Results of Spe ech Acts of Refusal:}

So to discuss the results of Pakistani EFL learner it can be said that instead of using the indirect refusal strategy for the face saving purpose they used direct refusal unlike the native speakers. Students used the statement of regret while on the other hand results of the study conducted on the native speakers shows that they do not the use the statement of regret with the lower or equal level participant. So overall it can be discussed that EFL learner's pragmatic comprehension and production of speech acts is very weak. As a major study carried out in Iran on the speech acts of refusal by (Allami \& Naiemi, 2011) also concludes that there is pragmatic transfer as well as there is major difference between the refusal strategies used by native speakers of English and Iranian English learners. Use of regret is in relevance to the Iranian speakers and unlike the native speakers as it is 
mentioned in a study "Pragmatic Competence in the Target Language: A Study of Iranian Learners of English" by (Taghizadeh, 2017).

Data Analys is of Spe ech Acts of Apology:

Overall Analysis of Speech Acts of Apology:

\begin{tabular}{lllll}
\hline Apologies Strategies & \multicolumn{2}{l}{50 Pakistani EFL learners } & \multicolumn{2}{l}{ 29 Native Speakers } \\
& Number & Percentage & Number & Percentage \\
\hline IFID & 207 & $59 \%$ & 28 & $97 \%$ \\
Explanation & 128 & $36 \%$ & 7 & $23 \%$ \\
Repair & 82 & $23 \%$ & 16 & $55 \%$ \\
Responsibility & 50 & $14 \%$ & 6 & $21 \%$ \\
Forbearance & 12 & $3 \%$ & 2 & $7 \%$ \\
\hline
\end{tabular}

Table is adopted from Cohen et al. (1986)

Overall results of speech acts of apologies show that Pakistani EFL learners mostly used

IFID's as an apology strategy. Second most used apology strategy is explanation; its usage is $36 \%$. If we compare the result with the native speakers then we can say that Pakistani EFL learners used more explanation strategy then the native speakers. Pakistani learners used less specific or unspecific repair as it is $23 \%$ while native speakers with same situations used it for $(55 \%)$. Participants who accepted the responsibility is only $14 \%$ while more native speakers accepted the responsibility. And only $3 \%$ participants promised for not committing the same error in the future which is the lowest strategy used by Pakistani EFL learners.

\section{Results of Spe ech Acts of Apology:}

Data analysis of speech acts of apologies indicates that Pakistani EFL learners mostly used IFID's as an apology strategy. The second most used apology strategy is explanation that its usage is $36 \%$. If we compare the result with the native speakers then we can say that Pakistani EFL learners used more explanation strategy then the native speakers. Pakistani learners used less specific or unspecific repair as it is $23 \%$ while native speakers with same situations used it for (55\%). Participants who accepted the responsibility is only $14 \%$ while more native speakers accepted the responsibility. And only $3 \%$ participants promised for not committing the same error in the future which is the lowest strategy used by Pakistani EFL learners.

Discussion on the Results of Spe ech Acts of Apology:

Data analysis and results show that Pakistani EFL learners used more explanation and less IFID's in a situation where apologizer is enjoying social power and high status. In a situation where offender is of low status and offended enjoying the social power EFL learner used less explanation than the natives and in IFID's they used intensity of apology which is not used by the natives. EFL learners offered statement of repair less than the native speakers. Acceptance of responsibility and promise of forbearance is used less by the EFL learners if compared with the native speakers. In a situation where the apologizer is higher in social status and power, EFL learners used less IFID's and used intensity of apology while natives used more IFID's and no intensity of apology. EFL learners used less explanation and natives more where there the apologized is of high status. Offer of repair and promise of forbearance is very low if compared with the native speakers.

\section{Results of Likert Scale Questionnaire:}

Results of Likert scale questionnaire reveal that Pakistani EFL learners have acknowledge that pragmatic knowledge of the target language is as important as other components like semantics, syntax and phonology. And majority of the English learners view is that Pakistani English textbooks used in language classrooms don't contain the cultural background of the target language as well as they lack the conversation rules and skills which are necessary for conversation in the practical life. And EFL learners demanded that cultural background should be a part of the English textbooks so that they may feel comfort while communication in the target language. A large number of the students considered it difficult to comprehend the pragmatic background of English words when they watch English movies, news and dramas. Majority of the population demanded that pragmatic knowledge should be a permanent part of language teaching like the teaching of other linguistic components. And many participants argued that they are unsatisfied with the teaching and learning environment as it fails to enable them for appropriate communication because the culture of the target language is not discussed in the language classrooms. Pakistani EFL learners acknowledged the fact that for the appropriateness in communication pragmatic knowledge is significant. Results indicate 
that majority of the EFL learners expressed that they have to face difficulties in comprehending the intended meanings while communicating in the target language.

\section{Discussion on the Results of Likert Scale Questionnaire:}

Data analysis of the Likert scale questionna ire indicates that Pakistani EFL learner's perceptions and choices regarding the teaching and learning of English have been changed gradually. As for a long time they have been taught through the old methods like the Grammar Translation method without using new techniques and technologies, especially regarding the pragmatics, as now they want to be taught not by the traditional approaches but by the student centered and pragmatic approaches. EFL learners have acknowledged the significance of the pragmatic competence for the purposeful and effective communication in the target language that is the reason they now want pragmatic knowledge and cultural components to be discussed in the language classrooms as well as they want these to be discussed outside the classroom. The study's result are in accordance with previous studies like ("Pragmatics, Perceptions and Strategies in Chinese College English Learning" by (Yifeng Yuan, 2012). The results are in line with (Savignon and Wang, 2003) as cited in (Valeo, A., \& Spada, N., 2016) which conclude that they found differences between preferences and needs of English learners and their views regarding the teaching and learning strategies especially regarding pragmatic knowledge.

\section{Conclusion:}

Pakistani EFL learners acknowledged that pragmatic knowledge is as important as linguistic know ledge for effective communication in the target language. It is very difficult for the EFL learners to comprehend the intended meanings when they listen news and watch movies. It is also accepted by the EFL learners that they have to face difficulties in comprehending and communicating in the target language. Majority of the students argued that pragmatic failure happens because they are not taught in the language classroom that how to use it appropriately as well as they are not satisfied with the tasks and activities used in the language classrooms. Most of the EFL teachers do not discuss the target culture or knowledge in the classrooms. It is also concluded that English textbooks lack the information on culture, and conversation rules of the target language.

The study through the speech acts analyzes the refusal and apology strategies used by learners and conclude that most of the EFL learners failed to comprehend the intended meanings and their replies show that they have very poor knowledge of the target language especially when it comes to real life-like contexts. So it can be said that pragmatic competence level of Pakistani EFL learner's is very low as they have very poor performance in comprehending and producing the appropriate language. Therefore they have to face pragmatic failures outside the classrooms when they communicate in the target language.

\section{References:}

Allami, H., \& Naeimi, A. (2011). A cross-linguistic study of refusals: An analysis of pragmatic competence development in Iranian EFL learners. Journal of pragmatics, 43(1), 385-406.

Bardovi-Harlig, K. (1996). Pragmatics and Language Teaching: Bringing Pragmatics and Pedagogy Together.

Bardovi-Harlig, K., \& Hartford, B. (1997). Beyond Methods: Components of Second Language Teacher Education. The McGraw-Hill Second Language Professional Series.

Directions in Second Language Learning and Teaching. McGraw-Hill Companies, Inc., Order Services, PO Box 545, Blacklick, OH 43004-0545.

Bardovi-Harlig, K. (2002). A new starting point: Investigating formulaic use and input in future expression. Studies in second language acquisition, 24(2), 189-198.

Bataineh, R. F., \&Bataineh, R. F. (2008). A cross-cultural comparison of apologies by native speakers of American English and Jordanian Arabic. Journal of pragmatics, 40(4), 792-821.

Beebe, L. M., Takahashi, T., \& Uliss-Weltz, R. (1990). Pragmatic transfer in ESL refusals. Developing communicative competence in a second language, 5573.

Blum-Kulka, S., House, J., \& Kasper, G. (1989). Cross-cultural pragmatics: Requests and apologies (Vol. 31). Ablex Pub.

Brown, K. (2009). Concise encyclopedia of pragmatics. Elsevier.

Canale, M. (1983). From communicative competence to language pedagogy' in J. Richards and R. Schmidt. Language and Communication. 
Canale, M. (1987). The measurement of communicative competence. Annual review of applied linguistics, 8, 67-84.

Canale, M., \& Swain, M. (1980). Theoretical bases of communicative approaches to second language teaching and testing. Applied linguistics, 1(1), 1-47.

Cohen, A. D., Olshtain, E., \& Rosenstein, D. S. (1986). Advanced EFL apologies: what remains to be learned? International Journal of the Sociology of Language, 1986(62), 51-74.

Council of Europe. Council for Cultural Co-operation. Education Committee. Modern Languages Division. (2001). Common European Framework of Reference for Languages: learning, teaching, assessment. Cambridge University Press.

Dörnyei, Z. (2007). Research methods in applied linguistics: Quantitative, qualitative, and mixed methodologies (pp. 95-123). Oxford: Oxford University Press.

Kasper, G., \& Blum-Kulka, S. (1993).Inter-language pragmatics: An introduction. Interlanguage pragmatics, 3,15 .

Kasper, G., \& Rose, K. R. (2002). Pragmatic Development in a Second Language. Language Learning: A Journal of Research in Language Studies, 52, 1.

Kasper, G., \& Dahl, M. (1991). Research methods in inter-language pragmatics. Studies in Second Language Acquisition, 13(2), 215-247.

Leech, G. (1987). N. (1983) Principles of Pragmatics. London: Longman.

Liu, J. (2004). Measuring inter-language pragmatic knowledge of Chinese EFL learners (Doctoral dissertation, City University of Hong Kong).

Miller, D. (1974). On the comparison of false theories by their bases. The British Journal for the Philosophy of Science, 25(2), 178-188.

O'Keeffe, A., Clancy, B., \& Adolphs, S. (2011). Introducing pragmatics in use. Routledge.

Taghizadeh, R. (2017). Pragmatic competence in the target language: a study of Iranian learners of English (Doctoral dissertation, University of Salford).

Thomas, J. (1983). Cross-cultural pragmatic failure. Applied linguistics, 4(2), 91-112.

Valeo, A., \& Spada, N. (2016). Is there a better time to focus on form? Teacher and learner views. TESOL Quarterly, 50(2), 314-339.

Yuan, Y. (2012). Pragmatics, perceptions and strategies in Chinese college English learning (Doctoral dissertation, Queensland University of Technology). 